\begin{tabular}{|c|l|}
\hline Title & Two imbibition properties independently influence the cultivar-specific flooding tolerance of dried soybean seeds \\
\hline Author(s) & Jitsuyama, Yutaka; Hagihara, Y uma; Konno, Y utaro \\
\hline Citation & $\begin{array}{l}\text { Seed Science Research, 24(1), 37-48 } \\
\text { https://doi.org/40.1017/S0960258513000378 }\end{array}$ \\
\hline Issue Date & 201403 \\
\hline Doc URL & http://hdl.handle.net/2115/55518 \\
\hline Rights & ○ Cambridge University Press 2014 \\
\hline Type & article \\
\hline File Information & seed science research 2014.pdf \\
\hline
\end{tabular}

Instructions for use 


\section{Seed Science Research}

http://journals.cambridge.org/SSR

Additional services for Seed Science Research:

Email alerts: $\underline{\text { Click here }}$

Subscriptions: $\underline{\text { Click here }}$

Commercial reprints: Click here

Terms of use : $\underline{\text { Click here }}$

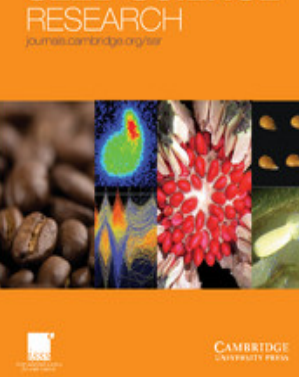

\section{Two imbibition properties independently influence the cultivar-specific flooding tolerance of dried soybean seeds}

Yutaka Jitsuyama, Yuma Hagihara and Yutaro Konno

Seed Science Research / Volume 24 / Issue 01 / March 2014, pp 37 - 48

DOI: 10.1017/S0960258513000378, Published online: 17 February 2014

Link to this article: http://journals.cambridge.org/abstract_S0960258513000378

How to cite this article:

Yutaka Jitsuyama, Yuma Hagihara and Yutaro Konno (2014). Two imbibition properties independently influence the cultivarspecific flooding tolerance of dried soybean seeds . Seed Science Research, 24, pp 37-48 doi:10.1017/

S0960258513000378

Request Permissions : $\underline{\text { Click here }}$ 


\title{
Two imbibition properties independently influence the cultivar-specific flooding tolerance of dried soybean seeds
}

\author{
Yutaka Jitsuyama $^{1 *}$, Yuma Hagihara ${ }^{2}$ and Yutaro Konno ${ }^{2}$ \\ ${ }^{1}$ Research Faculty of Agriculture, Research Group of Botany and Agronomy, Hokkaido University, Sapporo \\ 060-8589, Japan; ${ }^{2}$ School of Agriculture, Department of Agrobiology and Bioresources, Hokkaido University, \\ Sapporo 060-8589, Japan
}

(Received 24 July 2013; accepted after revision 25 November 2013)

\begin{abstract}
Soybean seeds are prone to flooding injury just after planting if they are exposed to excess moisture. We investigated the flooding tolerance of soybean seeds to clarify the relationship between flooding injury and imbibition, to identify factors that could provide fundamental information for the breeding of floodingtolerant cultivars. Seven cultivars were used for this study. The seeds were geminated in a paper towel after a flooding treatment and then evaluated for survival. The imbibition of submerged seeds (passive imbibition) was evaluated as the seed fresh weight change during the flooding process. The imbibition of seeds with capillary effect (capillary imbibition) was measured by the bottom water supply method. Furthermore, the conductivity of the seed coat and seed osmolarity were measured. After $3 \mathrm{~h}$ of flooding, significant differences in survival were detected among cultivars. In addition, the passive imbibition during 10-30 min of flooding, and the capillary imbibition during $0-10$ min of flooding were caused by significant differences in the imbibition rate among cultivars. Although neither imbibition showed a significant correlation with the survival directly, the ratio between the passive and the capillary imbibition rate was significantly correlated with survival. Factors affecting imbibition included the hydraulic conductivity of the seed coat and seed osmolarity, which were significantly correlated with the passive and the capillary imbibition rate, respectively. Thus, the balance between the capillary and passive imbibition behaviour of seeds, affected by the hydraulic conductivity of the seed coat and seed osmolarity, was closely correlated with the occurrence of flooding injury in soybean seeds.
\end{abstract}

*Correspondence

Email: y-jitsu@re.agr.hokudai.ac.jp
Keywords: capillary imbibition, Glycine max (L.) Merr., hydraulic conductivity, moisture treatment, osmolarity, seed coat

\section{Introduction}

Soybeans are an internationally important food, fodder and industrial crop and a useful source of vegetable oil and protein. Traditional Japanese food culture has developed with soybeans, making it an irreplaceable crop that can be connected directly with Japanese life. However, the current self-sufficiency rate (calorie base) for soybean in Japan is 6\%, which is remarkably lower than that for paddy rice, which is also a staple of Japanese food culture. The Ministry of Agriculture, Forestry and Fisheries of Japan proposed a policy that the targeted self-sufficiency rate for soybeans in 2020 be raised to 17\% (Ministry of Agriculture, Forestry and Fisheries of Japan, 2010); however, many problems related to production have blocked such an increase.

The effect of a policy of reduction of the acreage under rice cultivation since 1970 in Japan promoted the conversion to field from paddy field. Presently, over $80 \%$ of domestic soybean production comes from converted paddy fields following changes in paddy rice production (Ministry of Agriculture, Forestry and Fisheries of Japan, 2012). One of the problems for soybean production is closely related to the traits of these converted fields. The soil of converted fields includes a high fraction of heavy clay, reflecting their paddy field origin. Although soybean is more tolerant of excess moisture than other upland crops, flooding injury of soybean occurs and is affected by the duration of flooding (Scott et al., 1989), the ambient temperature (Wuebker et al., 2001), the coexistence of pathogens (Kato et al., 2013), the selection of cultivars (VanToai et al., 2010), drought conditions after flooding (Ministry of Agriculture, Forestry and Fisheries of Japan, 2005), 
and growth stage. Heavy, prolonged rain just after seeding can cause very conspicuous flooding injury in soybean seed, and drastically reduce soybean yield as a result of poor germination (Arihara et al., 2000).

Some current practices can avoid serious injury under these circumstances. Soybean seeds with a cracked seed coat are prone to non-germination under excess soil moisture; therefore, germination could be improved by removing cracked seeds before seeding (McDonald et al., 1988). Since quantitative trait locus (QTL) analysis of seed coat cracking or physiological factors has been advancing (Sayama et al., 2009; Oyoo et al., 2010), future genetic improvements are expected. If the depth of the water table in a converted field can be freely controlled in soybean cultivation, the productivity can be stable. The FOEAS (Farm-Oriented Enhancing Aquatic System) is a field-engineering practice based on this idea (Matsuo et al., 2013). Soaking soybean seeds in hypertonic solution before planting has been found to be an artificial pretreatment that improves the flooding tolerance of seeds (Woodstock and Taylorson, 1981). Also, 'highmoisture treatment' for soybean seed has attracted attention for a long time as an effective and simple pretreatment that has the same effect as the hypertonic method (Obendorf and Hobbs, 1970; Vertucci and Leopold, 1984). Flooding injury could be reduced by moisture treatment in which the moisture content of seeds is raised to approximately 15\% (Toledo et al., 2010). Such technological improvements are useful in avoiding flooding injury, but further improvements and progress are needed. However, debatably, scientific breeding for flooding tolerance in susceptible cultivars could be important. Basic information on the injury-causing mechanism is essential for this, but there are still many unknowns.

Generally, the progress of seed germination has multiple phases (Weitbrecht et al., 2011). Phase I begins just after water is absorbed by a seed, and consists of two processes: the first involves the rapid uptake of water (imbibition) and the second involves a linear increase in seed moisture content. After phase I, seeds almost entirely cease water uptake in phase II, and radicle emergence begins in the post-germination stage of phase III. In this report, we focused on the first process (phase I) because the rapid water influx during this phase occurs in dead seeds (Krishnan et al., 2004).

The cause of soybean seed flooding injuries has been examined in many studies. What is known about the mechanism is that sudden and rapid imbibition begins just after flooding of the seed, and imbibition induces the collapse of the cotyledons and the embryonic axis, preventing germination (Woodstock and Taylorson, 1981; Nakayama and Komatsu, 2008). The damage is greater in low-moisture than in highmoisture seeds (Ishibashi et al., 2005). Furthermore, some other factors related to soybean seed flooding injury include low oxygen conditions (Tian et al., 2005) and the induction of pathogens by leakage from damaged cells (Kato et al., 2013).

Differences in the flooding injury of soybean seeds have been reported (Hou and Thseng, 1991; Tian et al., 2005), and the key factor affecting the injury is the difference among cultivars and the seed waterabsorbing rate (Hou and Thseng, 1991; Tian et al., 2005). The consistent tendency is for the rate of imbibition to be slower in flooding-tolerant cultivars than in susceptible cultivars. That is, the imbibition is slow enough so that the cotyledons will not break. Furthermore, the imbibition behaviour of soybean seeds can be affected by substances on the seed coat (Mullin and Xu, 2001; Shao et al., 2007; Ranathunge et al., 2010; Zhou et al., 2010), the seed coat colour (Hou and Thseng, 1991; Chachalis and Smith, 2000), the region of the seed surface (Meyer et al., 2007; Muramatsu et al., 2008), the micro-structure (Yaklich et al., 1986; Ma et al., 2004) or the inner layer (Koizumi et al., 2008) of the seed coat, the adhesion between the seed coat and cotyledon (Chachalis and Smith, 2000; Nakayama and Komatsu, 2008) and the hydraulic conductivity of the seed coat (Meyer et al., 2007). Based on these findings, it is possible that seed traits that affect imbibition behaviour might determine the flooding tolerance of soybeans. Although there could be multiple strategies for soybean cultivars against excess soil moisture, a complete analysis of the mechanisms causing flooding injury is not available at present.

In the present study, we have attempted to clarify the relationship between flooding injury of soybean seeds and imbibition, as well as the traits that influence imbibition. For this purpose, we used moisture-treated soybean seeds of seven cultivars and compared their flooding tolerance, imbibition behaviour and seed traits, and determined their relationships.

\section{Materials and methods}

\section{Plant materials and moisture treatment}

To investigate the flooding tolerance of moisturetreated soybean (Glycine max (L.) Merr.) seeds, seven soybean cultivars were studied (Table 1). Coloured, stained, wounded or otherwise abnormal seeds were removed, and the normal seeds were stored in a refrigerator at $4^{\circ} \mathrm{C}$. We checked that these normal seeds of all cultivars had a $90-100 \%$ germination rate with incubation on a wet Petri dish at $25^{\circ} \mathrm{C}$ in the dark for $3 \mathrm{~d}$.

As a pre-treatment before all experiments, seeds were moisture treated either in high- or low-moisture conditions for adjustment of their moisture content. In the case of high-moisture treatment, 60 seeds were incubated in a sealed plastic container with a plate containing $15 \mathrm{ml}$ water at $25^{\circ} \mathrm{C}$ in the dark for $3 \mathrm{~d}$. 
Table 1. Basic information about the seeds of the seven soybean cultivars used in this study

\begin{tabular}{llll}
\hline Cultivar $^{\mathrm{a}}$ & Abbreviation & Flooding tolerance & Other traits \\
\hline Toyomusume & TMu & Susceptible & Popular cultivar with good taste from Hokkaido prefecture \\
Enrei & ERe & Susceptible & Standard cultivar \\
Fukuyutaka & FYu & Tolerant-like & Standard cultivar \\
Hayahikari & HHi & Tolerant & Cold tolerant in blooming stage \\
Naksennari & NSe & Susceptible & Rare cultivar with good taste from Nagano prefecture \\
Suzumaru & SMa & $-{ }^{c}$ & Small-seed cultivar, for comparison with PKi \\
Peking & PKi & Tolerant & Black, small-seed cultivar from China, for fodder \\
\hline
\end{tabular}

a Cultivars are displayed in order of seed mass (see Table 2).

${ }^{\mathrm{b}}$ Flooding tolerance derived from previous research (Tian et al., 2005; our unpublished data).

- , unknown.

Low-moisture treated seeds were created by incubation of 60 seeds with $15 \mathrm{~g}$ of fresh silica gel particles.

\section{Flooding treatment and germination test}

The flooding tolerance of soybean seeds was elucidated in detail for various flooding durations using the paper towel method, basically according to the International Seed Testing Association rules (ISTA, 1985). After the moisture treatment, seeds were immediately immersed in distilled water for $10 \mathrm{~min}, 1 \mathrm{~h}, 3 \mathrm{~h}$ or $24 \mathrm{~h}$ at $25^{\circ} \mathrm{C}$ in the dark. Seeds without a flooding treatment were prepared as control samples. All these seeds were coated with Benlate T (Sumitomo Kagaku Co., Ltd, Tokyo, Japan) for sterilization before the germination test. Ten seeds were arranged on one piece of paper towel with sticky-tape, a part of the paper towel was soaked with tap water, and this was incubated at $25^{\circ} \mathrm{C}$ in the dark for a week. The germination rate was calculated by counting the normally germinating plantlets, defined as those with no damage to the cotyledons and with normal elongation of the infant root. The germination test was conducted with three replicates (ten seeds per replicate) in a complete randomized block design.

\section{Seed moisture content and seed volume}

Some of the moisture-treated seeds were weighed to obtain their fresh weight and dry weight. To measure dry weight, seeds were dried completely at $80^{\circ} \mathrm{C}$ for $2 \mathrm{~d}$ or more. The moisture content of the seeds was calculated from the fresh and dry weight after the moisture treatment. The measurements of fresh and dry weights were repeated with three replicates each (ten seeds per replicate).

The fresh weight of the seeds was also used for measuring the volume after the moisture treatment. To measure seed volume, ten seeds were put into a waterfilled 50-ml measuring cylinder, and the increased volume of the water was measured. Although the method was not very sensitive, air bubbles on the seed surface were removed before measurement to maximize the accuracy as much as possible. The volume measurement was repeated three times with ten seeds per replicate.

\section{Passive imbibition}

In the present study, we measured two types of imbibition behaviour: passive imbibition, that which occurred in submerged (flooded) seeds, and capillary imbibition, where seeds absorbed water by capillarity. As we also wanted to compare two types of imbibition behaviour, we devised a methodology for measuring passive imbibition separately in six regions (Fig. 1A) of the seed surface and defined the passive imbibition as the average ratio of the regions. First, seeds were coated with water-repellent resin (silicon lacquer spray, Kanpe-hapio Co., Ltd, Oosaka, Japan) except for the seed surface region where imbibition would take place. After the seed coating, a circle-shaped area $2-5 \mathrm{~mm}$ in diameter was left exposed on the intact seed coat of each seed. The exposed seed coats in the circle were checked for a normal appearance with a microscope, and only normal seeds were moisturetreated before the measurement of passive imbibition. The low-moisture seeds were weighed and then promptly immersed in distilled water. Subsets of the seeds were removed from the water after $10 \mathrm{~min}$, $30 \mathrm{~min}, 1 \mathrm{~h}$ and $3 \mathrm{~h}$. The water adhering to lifted seeds was carefully wiped off with Kimwipes, and the seeds were weighed with an electric balance with a sensitivity of $0.01 \mathrm{mg}$ (R180D, Sartorius AG, Göttingen, Germany). The passive imbibition was expressed as the water volume per average fresh seed weight and unit time $\left[\mu \mathrm{l}(\mathrm{g} \mathrm{FW})^{-1} \mathrm{~min}^{-1}\right]$. The measurement of passive imbibition was repeated eight times with ten seeds per replicate.

\section{Capillary imbibition}

Capillary imbibition was also measured separately for the six regions (Fig. 1A) and averaged among them, 
A

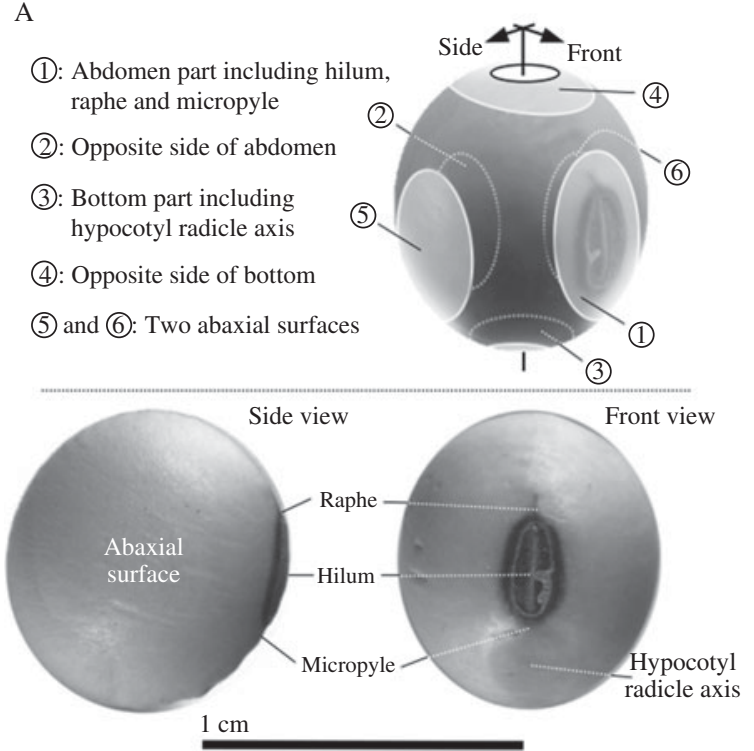

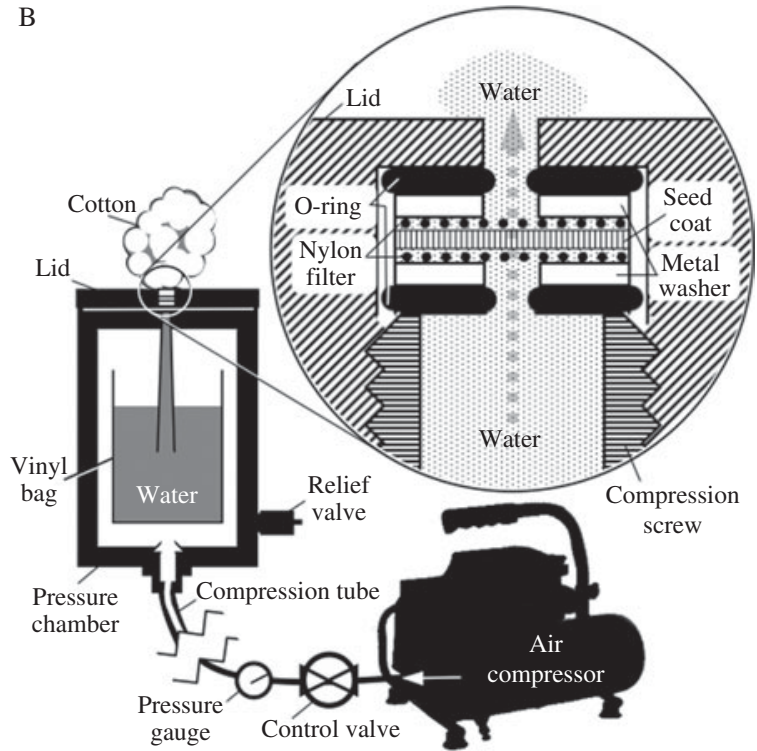

Figure 1. Photograph showing each separate part used to measure imbibition behaviour, using a 'Hayahikari' seed as a model (A), and a diagram of the instrument used to measure the hydraulic conductance of seed coats (B). In B, distilled water was incorporated into a bag in a pressure chamber. A seed coat was sandwiched with O-rings, a metal washer and a nylon filter, and then the assembly was tightened by compression screwing. Water was forced into the upper part by pressure from an air compressor. Water that passed through the seed coat and nylon filters was absorbed by cotton, which was then weighed.

using the bottom water supply method (Nakayama and Komatsu, 2008). The low-moisture seeds were weighed and promptly placed on water-saturated cotton touching a certain seed partial surface that let the area imbibe. Subsets of the seeds were taken off the cotton after $10 \mathrm{~min}, 30 \mathrm{~min}, 1 \mathrm{~h}, 3 \mathrm{~h}$ and $6 \mathrm{~h}$, and were weighed and calculated in the same way as for passive imbibition. We defined the seed-specific capillary imbibition as the average ratio of the regions of the seed. The measurement of capillary imbibition was repeated five times with one seed per replicate.

\section{Hydraulic conductance of the seed coat}

We measured the hydraulic conductance of the seed coat because the permeability of the seed coat to water would be of great importance for the imbibition behaviour of soybean seeds. In the present study, we measured the hydraulic conductance of the seed coat directly using a modified pressure chamber (Fig. 1B). A piece of the seed coat from the abaxial surface of a low-moisture seed was cut to $5 \mathrm{~mm}$ in diameter using a cork borer. The disc of the specimen was hydrated with distilled water until setting it up in the chamber lid of a pressure chamber. To protect the seed coat against uneven pressure, each disc was sandwiched between nylon discs (NRS-050, aperture: $50 \mu \mathrm{m}$; wire diameter: $38 \mu \mathrm{m}$; Nippon Rikagaku Kikai Co., Ltd, Tokyo, Japan), and was attached to the lid with metal washers and O-rings to make the chamber airtight. In the lid, a water-filled tube was placed by the seed coat disc so that the water would come up to the disc during pressurization. Pressure in the chamber was gradually increased to $100 \mathrm{kPa}$ and maintained for $5 \mathrm{~min}$, using a commercial air compressor (AM02-04N, Fujiwara Sangyo Co., Ltd, Hyogo, Japan). We trapped the water discharged through the seed coat for $5 \mathrm{~min}$ using pre-weighed cotton. The cotton was weighed with an electric balance with a sensitivity of $1 \mathrm{mg}$ (VIC212, ACCULAB, Sartorius AG). The hydraulic conductance of the seed coat was represented as the water volume per unit time and pressure $\left(\mu 1 \mathrm{kPa}^{-1} \mathrm{~min}^{-1}\right)$. The measurement was conducted six times with a single seed coat disc per replicate.

\section{Seed osmolarity}

We also measured the osmolarity inside soybean seeds as a factor that could affect the capillary imbibition behaviour. After moisture treatment, a 5-mm cube of the cotyledonary centre was cut from the seed, and the fresh weight was measured. The fraction of the cotyledon was put into a $0.5-\mathrm{ml}$ Eppendorf tube with $200 \mu \mathrm{l}$ of Mili Q water, and frozen at $-80^{\circ} \mathrm{C}$. After thawing, the tube was treated with ultrasonic cleaning equipment (CS-20, OMRON Co., Kyoto, Japan) for $10 \mathrm{~min}$ to release the water-soluble substances into solution from the cotyledonary tissue. Ten microlitres of the solution was loaded in an osmometer (VAPRO type 5600, Wescor Inc., Logan, Utah, USA) to measure the osmolarity. The osmolarity was expressed as the value per gram fresh weight of cotyledonary tissue 
$\left[\mathrm{mol} \mathrm{kg}^{-1}(\mathrm{~g} \text { FW seed })^{-1}\right]$. The measurement was conducted ten times with one cotyledonary cube from a seed per replicate.

\section{Statistical analysis}

The experimental arrangement was based on a complete randomized design with 3-10 replicates, depending on the measurement. A Student's t-test, Tukey-Kramer's test, analysis of variance (ANOVA) and Pearson's correlation coefficient were conducted using the statistics software SPSS (v. 20.0, IBM SPSS, Tokyo, Japan).

\section{Results}

\section{Effect of moisture treatment on basic traits of soybean seeds}

Seeds after moisture treatment were measured for seed mass (weight of 100 seeds), moisture content and seed volume (Table 2). ANOVA showed that the effects of cultivar or treatment on all seed traits were significant, as well as the interactive effects between cultivar and treatment on seed mass $(P<0.05)$. In comparing the two moisture treatments, low-moisture seeds had lower moisture content $(P<0.01)$ and smaller seed mass $(P<0.001)$ than high-moisture seeds. The seed volume also swelled in the high-moisture seeds $(P<0.001)$. In comparing among cultivars, significant differences in all seed traits were detected $(P<0.001)$. Initial moisture content in seeds was adjusted to about $5 \%$ (low) and 13\% (high) water (fresh mass basis). However, the magnitude of difference in weight and volume between the two moisture treatments depended upon cultivar. The differences related to the swelling ratio of the seed volume, which varied from 1.075 (NSe) to 1.255 (SMa).

\section{Effect of moisture treatment on soybean seed survival under flooding}

We checked seed survival, that is, the rate of germination into normal seedlings, after the various durations of flooding treatment for the different moisture-treated seeds (Fig. 2). Survival decreased with increased flooding duration up to $24 \mathrm{~h}$ for lowmoisture seeds, but high-moisture seeds were not affected by flooding. There were significant

Table 2. Basic information about the moisture-treated seeds of the seven soybean cultivars

\begin{tabular}{|c|c|c|c|c|c|c|c|c|c|c|c|}
\hline \multirow{4}{*}{$\frac{\text { Cultivar }^{\mathrm{a}}}{\mathrm{TMu}}$} & \multirow{3}{*}{$\frac{\text { Treatment }^{\mathrm{b}}}{\mathrm{H}}$} & \multicolumn{10}{|c|}{ Seed traits } \\
\hline & & \multicolumn{3}{|c|}{$\begin{array}{c}\text { Weight } \\
\text { of } 100 \text { seeds }(g)\end{array}$} & \multicolumn{3}{|c|}{$\begin{array}{c}\text { Moisture } \\
\text { content (\%) }\end{array}$} & \multicolumn{3}{|c|}{$\begin{array}{c}\text { Volume } \\
\text { of } 10 \text { seeds }\left(\mathrm{cm}^{3}\right)\end{array}$} & \multirow{2}{*}{$\frac{\text { Swelling ratio }^{c}}{1.129}$} \\
\hline & & 42.1 & $(0.4)^{\mathrm{d}}$ & *e & 13.2 & $(0.2)$ & $* * *$ & 3.50 & $(0.06)$ & * & \\
\hline & L & 38.3 & $(0.6)$ & & 6.1 & $(0.2)$ & & 3.10 & $(0.06)$ & & \\
\hline \multirow[t]{2}{*}{ ERe } & $\mathrm{H}$ & 32.5 & $(1.0)$ & * & 12.6 & $(0.5)$ & $* *$ & 2.70 & $(0.06)$ & * & 1.125 \\
\hline & $\mathrm{L}$ & 30.6 & $(0.7)$ & & 4.8 & $(0.0)$ & & 2.40 & $(0.06)$ & & \\
\hline \multirow[t]{2}{*}{ FYu } & $\mathrm{H}$ & 32.6 & $(0.7)$ & * & 13.5 & $(0.2)$ & $* * *$ & 2.70 & $(0.06)$ & $* *$ & 1.174 \\
\hline & $\mathrm{L}$ & 30.1 & $(0.3)$ & & 5.4 & $(0.1)$ & & 2.30 & $(0.06)$ & & \\
\hline \multirow[t]{2}{*}{$\mathrm{HHi}$} & $\mathrm{H}$ & 32.8 & $(0.5)$ & * & 13.6 & $(0.0)$ & $* * *$ & 2.40 & $(0.12)$ & * & 1.125 \\
\hline & $\mathrm{L}$ & 29.7 & $(0.5)$ & & 5.8 & $(0.0)$ & & 2.13 & $(0.07)$ & & \\
\hline \multirow[t]{2}{*}{ NSe } & $\mathrm{H}$ & 29.1 & $(0.5)$ & $\dagger$ & 12.6 & $(0.2)$ & $* * *$ & 2.40 & $(0.06)$ & + & 1.075 \\
\hline & $\mathrm{L}$ & 27.9 & $(0.4)$ & & 4.6 & $(0.2)$ & & 2.23 & $(0.03)$ & & \\
\hline \multirow[t]{2}{*}{ SMa } & $\mathrm{H}$ & 13.3 & $(0.2)$ & $* *$ & 13.8 & $(0.2)$ & $* * *$ & 1.15 & $(0.03)$ & $* *$ & 1.255 \\
\hline & $\mathrm{L}$ & 12.3 & $(0.2)$ & & 4.6 & $(0.0)$ & & 0.92 & $(0.02)$ & & \\
\hline \multirow[t]{2}{*}{ PKi } & $\mathrm{H}$ & 7.8 & $(0.2)$ & $t$ & 12.6 & $(0.4)$ & $* *$ & 1.03 & $(0.03)$ & * & 1.148 \\
\hline & $\mathrm{L}$ & 7.4 & $(0.1)$ & & 4.9 & (1.0) & & 0.90 & $(0.00)$ & & \\
\hline ANOVA $^{\mathrm{f}}$ & $\mathrm{df}$ & MS & $F$ & $P$ & MS & $F$ & $P$ & MS & $F$ & $P$ & \\
\hline C & 6 & 807.705 & 1065.408 & 0 & 1.312 & 4.627 & 0.003 & 0.774 & 97.041 & 0 & \\
\hline $\mathrm{T}$ & 1 & 42.2 & 55.644 & 0 & 662.355 & 2336.38 & 0 & 4.292 & 538.369 & 0 & \\
\hline $\mathrm{C} \times \mathrm{T}$ & 6 & 2.085 & 2.75 & 0.033 & 0.571 & 2.015 & 0.1 & 0.016 & 2.051 & 0.095 & \\
\hline
\end{tabular}

${ }^{a}$ Cultivars are displayed according to averaged seed mass.

${ }^{\mathrm{b}}$ Moisture treatment for high $(\mathrm{H})$ or low $(\mathrm{L})$ moisture seed conditions.

${ }^{c}$ Ratio of volume high/low moisture treatment.

${ }^{\mathrm{d}}$ Values in parentheses represent standard errors.

$e_{* * * * * * *}^{*}$, and + represent significant differences between $\mathrm{H}$ and $\mathrm{L}$ at the $0.1 \%, 1 \%, 5 \%$ and $10 \%$ levels, respectively $(n=3)$.

${ }^{\mathrm{f}}$ ANOVA was performed with the data set 7 cultivars $(\mathrm{C}) \times 2$ treatments $(\mathrm{T}) \times 3$ replicates (blocks) with a complete randomized design. df, degrees of freedom; MS, mean square; F, F value; and $P, P$ value. 


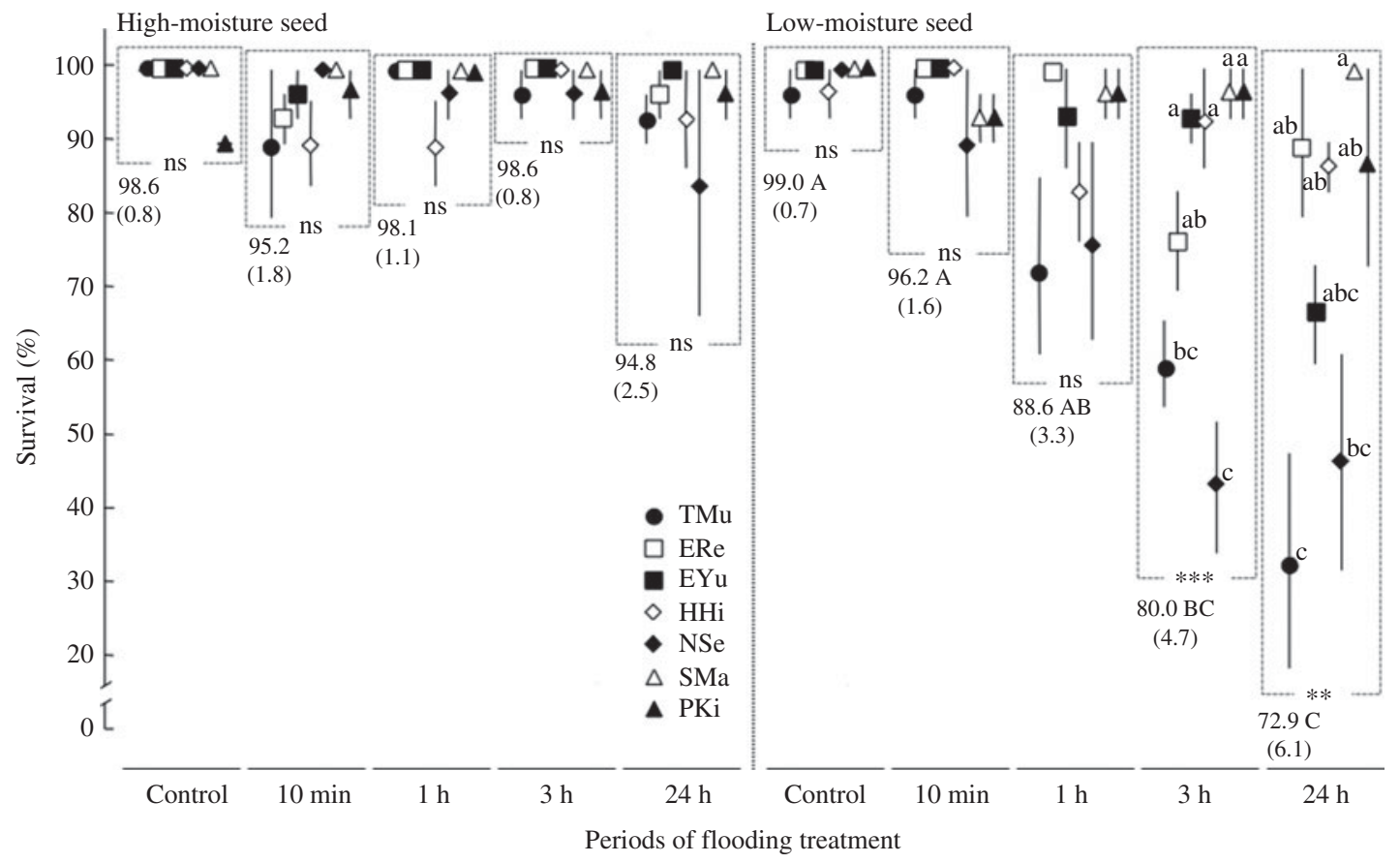

Figure 2. Changes in the survival of moisture-treated soybean seeds after flooding. The left and right figures show the results for high- and low-moisture seeds, respectively. Seven cultivars are represented by different symbols: $\bullet$, TMu 'Toyomusume'; $\square$, ERe 'Enrei'; $\mathbf{\square}$, FYu 'Fukuyutaka'; $\diamond$, HHi 'Hayahikari'; $\bullet$, NSe 'Nakasennari'; $\triangle$, SMa 'Suzumaru' and $\boldsymbol{\Delta}$, PKi 'Peking'. These symbols are arranged according to seed size (average weight of 100 seeds) shown in Table 1. Each value represents the mean of three replicates, and bars show standard errors. ${ }^{* *}$ and ${ }^{* *}$ accompanied by rectangles with a dotted boundary represent significant differences at the 0.001 and 0.01 probability level, respectively, among cultivars in the same duration of flooding, and the values with different small letters in rectangles are significantly different at the 0.05 probability level among the seven cultivars by a Tukey-Kramer's test $(n=3)$; ns denotes no significant difference. The averaged values are shown underneath rectangles, with standard errors in parentheses calculated from all values in the rectangle. Values with different capital letters underneath rectangles are significantly different at the 0.05 probability level by a Tukey-Kramer's test among the durations of the flooding treatment $(n=3)$.

cultivar-specific differences in the survival of lowmoisture seeds after $3 \mathrm{~h}$ of flooding. After 3 or $24 \mathrm{~h}$ of flooding, NSe and TMu displayed lower survival. In contrast, SMa and PKi had higher survival rates as compared with the other cultivars. According to the hypothesis that the flooding injury was induced by mechanical damage to cotyledons during imbibition, this indicated that the cultivar-specific differences in survival were induced by imbibition until $3 \mathrm{~h}$ of flooding. Next, we checked the time-lapse shifting of imbibition behaviour of low-moisture seeds, focusing particularly on passive imbibition during $3 \mathrm{~h}$ of flooding.

\section{Passive imbibition behaviour of low-moisture soybean seeds under flooding}

Passive imbibition rate was measured separately in six regions of the seed surface (Fig. 1A) to conform to measurements of capillary imbibition. No significant difference of imbibition rate was observed in the different surface regions just after submergence, during which the imbibition rate was fastest [passive imbibition: $P=0.227$ (not significant, ns); capillary imbibition: $P=0.913$ (ns), $n=56$, data not shown]. Thus, the results indicate that the effect of the seed surface region was small. The imbibition rates at different regions were then averaged and used for subsequent analysis.

Examining the shifts in passive imbibition rate during the first $3 \mathrm{~h}$ of flooding for low-moisture seeds, there was evidence of cultivar-specific differences in imbibition rate for flooding durations of $10-30 \mathrm{~min}$ (Fig. 3). Although there were cultivar-specific significant differences at the 0.05 level, a substantial difference could only be detected between TMu and PKi. The correlation between passive imbibition rate under flooding of 10-30 min and survival after $3 \mathrm{~h}$ of flooding, was not significant $\left[R^{2}=0.3215\right.$ (ns), $n=7$, data not shown], even though both showed significant cultivar-specific differences. Additionally, there was no duration of passive imbibition rate in any duration of flooding that showed a significant correlation with survival after $3 \mathrm{~h}$ of flooding. Thus, a conventional hypothesis that a single effect accompanied by passive 


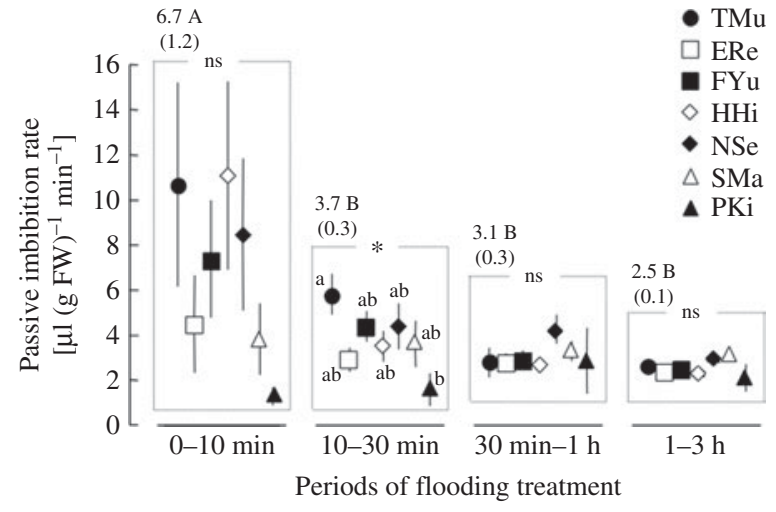

Figure 3. Changes in the passive imbibition rate of low-moisture soybean seeds during the flooding treatment. Seven cultivars are represented by symbols: $\bullet, \mathrm{TMu}$; $\square$, ERe; $\mathbf{\square}, \mathrm{FYu} ; \diamond, \mathrm{HHi} ; \diamond, \mathrm{NSe} ; \triangle$, SMa and $\boldsymbol{\Delta}, \mathrm{PKi}$. The arrangement of symbols is the same as for Fig. 1. Each value represents the mean of eight replicates, and bars show standard errors. ${ }^{*}$ accompanied by rectangles with a dotted boundary represents a significant difference at the 0.05 probability level among cultivars in the same duration of flooding treatment, and the values with different small letters are significantly different at the 0.05 probability level among the seven cultivars by a Tukey-Kramer's test $(n=8)$; ns denotes no significant difference. The averaged values are shown above rectangles, with standard errors in parentheses calculated from all values in a rectangle. Values with different capitals above rectangles are significantly different at the 0.05 probability level by a Tukey-Kramer's test among the durations of the flooding treatment $(n=8)$.

imbibition rate closely affected the flooding injury of soybean seeds could not be demonstrated in this study. Thus, we investigated another trait of imbibition behaviour of seeds, namely capillary imbibition.

\section{Capillary imbibition behaviour of low-moisture soybean seeds with bottom water supply}

Capillary imbibition behaviour was anticipated, because the seeds were allowed to absorb water from the bottom by capillarity. Therefore, we checked for capillary imbibition of low-moisture seeds at flooding durations of $6 \mathrm{~h}$. The trend of shifts in capillary imbibition in low-moisture seeds showed evidence of cultivar-specific differences in imbibition for all flooding durations, except for those of 10-30 min (Fig. 4). A remarkable cultivar-specific difference was shown in SMa, which tended to imbibe water faster than the other cultivars. However, the other cultivars with distinct seed flooding tolerances, i.e. TMu, NSe and $\mathrm{PKi}$, did not display distinct capillary imbibition rates. Similarly to the case of passive imbibition rate, the correlation between capillary imbibition rate under flooding of $0-10 \mathrm{~min}$ and survival after $3 \mathrm{~h}$ of flooding, was not significant $\left[R^{2}=0.2738(\mathrm{~ns}), n=7\right.$, data not shown], even though both showed significant cultivarspecific differences. And there was no duration of capillary imbibition rate in any duration of flooding that showed a significant correlation with survival after $3 \mathrm{~h}$ of flooding.

\section{Ratio of passive and capillary imbibition rate}

To further analyse the relationship between imbibition behaviour and seed flooding tolerance, we calculated the balance of two imbibition rates (passive/capillary ratio) related to survival after $3 \mathrm{~h}$ of flooding, using the ratio of passive imbibition to capillary imbibition (passive imibibition rate/capillary imbibition rate) with 20 combinations among four levels of passive imbibition and five levels of capillary imbibition. Four significantly negative correlations with survival after $3 \mathrm{~h}$ of flooding were found with passive/capillary ratio where the capillary imbibition during $0-10 \mathrm{~min}$ was used as the denominator $\left[0-10 \mathrm{~min}, R^{2}=0.6586\right.$ $(P<0.05) ; \quad 10-30 \mathrm{~min}, \quad R^{2}=0.7292 \quad(P<0.05)$; $30 \mathrm{~min}-1 \mathrm{~h}, R^{2}=0.5264(P<0.1) ; 1-3 \mathrm{~h}, R^{2}=0.6106$ $(P<0.05), n=7$, data not shown]. The remaining 16 combinations of passive and capillary imbibition did not show significant correlations with survival after

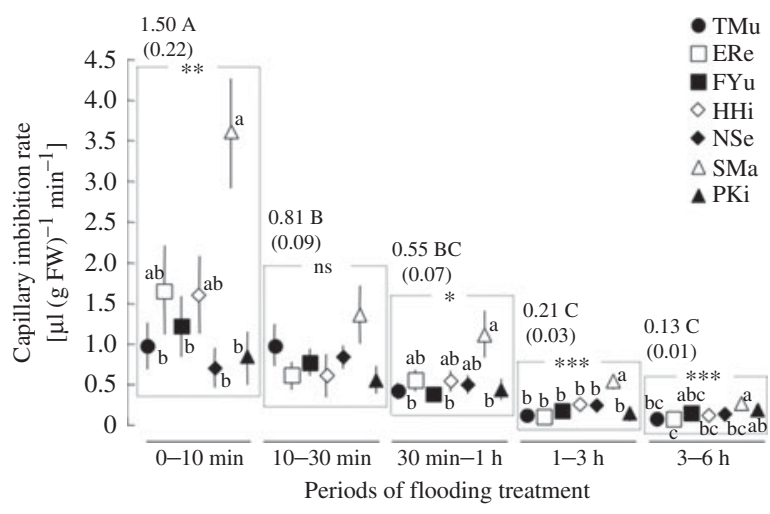

Figure 4. Changes in the capillary imbibition rate of lowmoisture soybean seeds during the flooding treatment. Seven cultivars were represented by symbols: $\bullet, \mathrm{TMu}$; $\square$, ERe; $\boldsymbol{\square}, \mathrm{FYu} ; \diamond, \mathrm{HHi} ; \bullet$ NSe; $\triangle$, SMa and $\boldsymbol{\Lambda}, \mathrm{PKi}$. The arrangement of symbols is the same as for Fig. 1. Each value represents the mean of five replicates, and bars show standard errors. * accompanied by rectangles with dotted boundaries represents a significant differences at the 0.05 probability level among cultivars in the same duration of the flooding treatment, and the values with different small letters are significantly different at the 0.05 probability level among the seven cultivars by a Tukey-Kramer's test $(n=5)$; ns denotes no significant difference. The averaged values are shown above rectangles, with standard errors in parentheses calculated from all values in a rectangle. These values with different capitals above rectangles are significantly different at the 0.05 probability level by a Tukey-Kramer's test among the periods of flooding treatment $(n=5)$. 
$3 \mathrm{~h}$ of flooding. The relationship between the survival after $3 \mathrm{~h}$ of flooding and the passive/capillary ratio (passive imbibition at $10-30 \mathrm{~min} /$ capillary imbibition at $0-10 \mathrm{~min}$ ) was the combination that showed the largest correlation coefficient with survival after $3 \mathrm{~h}$ of flooding (Fig. 5). The combination of passive/capillary ratio showed also a closer relationship with survival after $24 \mathrm{~h}$ of flooding. As is shown in Fig. 5, the susceptible cultivars such as NSe or TMu had a high passive/capillary ratio and low survival; in contrast, the tolerant cultivars like SMa or PKi had a low passive/capillary ratio and high survival. The ratio of imbibition rates suggests that the flooding injury of soybean seeds may become serious in cases of high passive imbibition or low capillary imbibition.

\section{Seed traits affected two imbibition behaviours each}

Next, we were interested in what kind of seed properties determined the extent of passive and capillary imbibition of soybean seeds. Among the various seed traits, the hydraulic conductivity of the seed coat and seed osmolarity surfaced as factors of particular interest. There were positive correlations between hydraulic conductivity of the seed coat and passive imbibition $\left[0-10 \mathrm{~min}, R^{2}=0.7493(P<0.05)\right.$ (Fig. 6A); $10-30 \mathrm{~min}, R^{2}=0.7138(P<0.05) ; 30 \mathrm{~min}-$ $1 \mathrm{~h}, R^{2}=0.0929$ (ns); $1-3 \mathrm{~h}, R^{2}=0.3404$ (ns), $\left.n=7\right]$ and between seed osmolarity and capillary imbibition $\left[0-10 \mathrm{~min}, R^{2}=0.4831(P<0.1) ; 10-30 \mathrm{~min}, R^{2}=\right.$ $0.9086(P<0.001)$ (Fig. 6B); $30 \mathrm{~min}-1 \mathrm{~h}, R^{2}=0.5947$
$(P<0.05) ; 1-3 \mathrm{~h}, R^{2}=0.6526(P<0.05) ; 3-6 \mathrm{~h}, R^{2}=$ 0.2227 (ns) $n=7]$.

To ensure the independence of each relationship, we checked the relationship between the two imbibition behaviours that were used as parameters of the passive/capillary ratio, and between the hydraulic conductivity and seed osmolarity, and in both cases the results were non-significant (Fig. 6C and D). Additionally, the correlation between hydraulic conductivity and passive imbibition was not significant $[0-10 \mathrm{~min}$, $R^{2}=0.0078$ (ns); $10-30 \mathrm{~min}, R^{2}=0.1581$ (ns); $30 \mathrm{~min}-$ $1 \mathrm{~h}, R^{2}=0.0033$ (ns); $1-3 \mathrm{~h}, R^{2}=0.1027$ (ns); 3-6h, $R^{2}=0.0350$ (ns), $n=7$, data not shown]. Although correlations between hydraulic conductivity and passive imbibition were subtly detected [0-10 $\mathrm{min}$, $R^{2}=0.4831 \quad(P<0.1) ; 10-30 \mathrm{~min}, R^{2}=0.2105$ (ns); $30 \mathrm{~min}-1 \mathrm{~h}, R^{2}=0.0454$ (ns); $1-3 \mathrm{~h}, R^{2}=0.5031$ $(P<0.1), n=7$, data not shown], the relationship with capillary imbibition seemed to be specific to seed osmolarity.

\section{Discussion}

\section{Importance of moisture treatment for soybean seed germination after flooding}

High-moisture treatment for soybean seeds before planting has a remarkable positive effect on later germination (Obendorf and Hobbs, 1970; Toledo et al., 2010). In the seven cultivars used for the present study, the effect of moisture treatments on the seed moisture content was clear, and the differences among
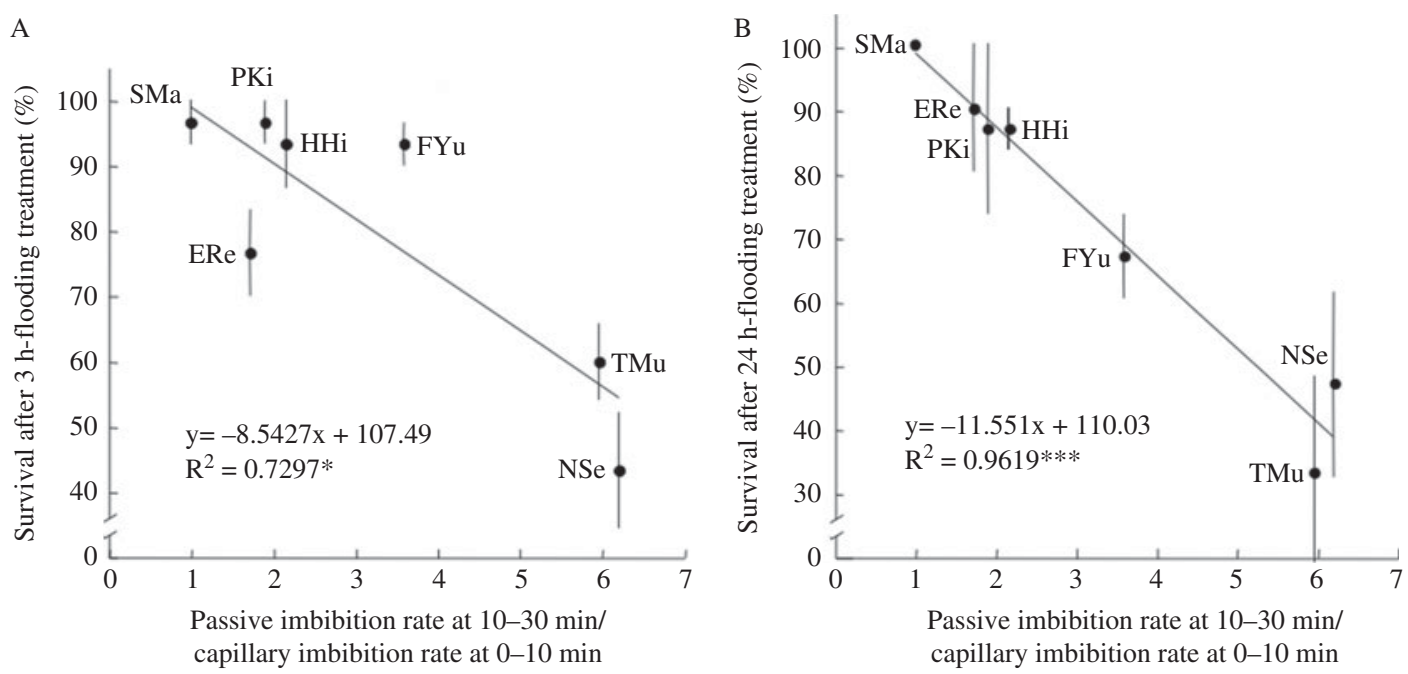

Figure 5. Relationships between passive imbibition rate at $10-30 \mathrm{~min} /$ capillary imbibition rate at $0-10 \mathrm{~min}$ and survival after $3 \mathrm{~h}$ of flooding (A), and survival after $24 \mathrm{~h}$ of flooding (B). Closed circle symbols represent each value, and the abbreviations of cultivars accompany these symbols. Data represents means from three replicates for survival. Bars show standard errors. A regression line shows a formula with significance at the 0.05 and 0.001 probability level (* and ***, respectively), by Pearson's correlation coefficient. 

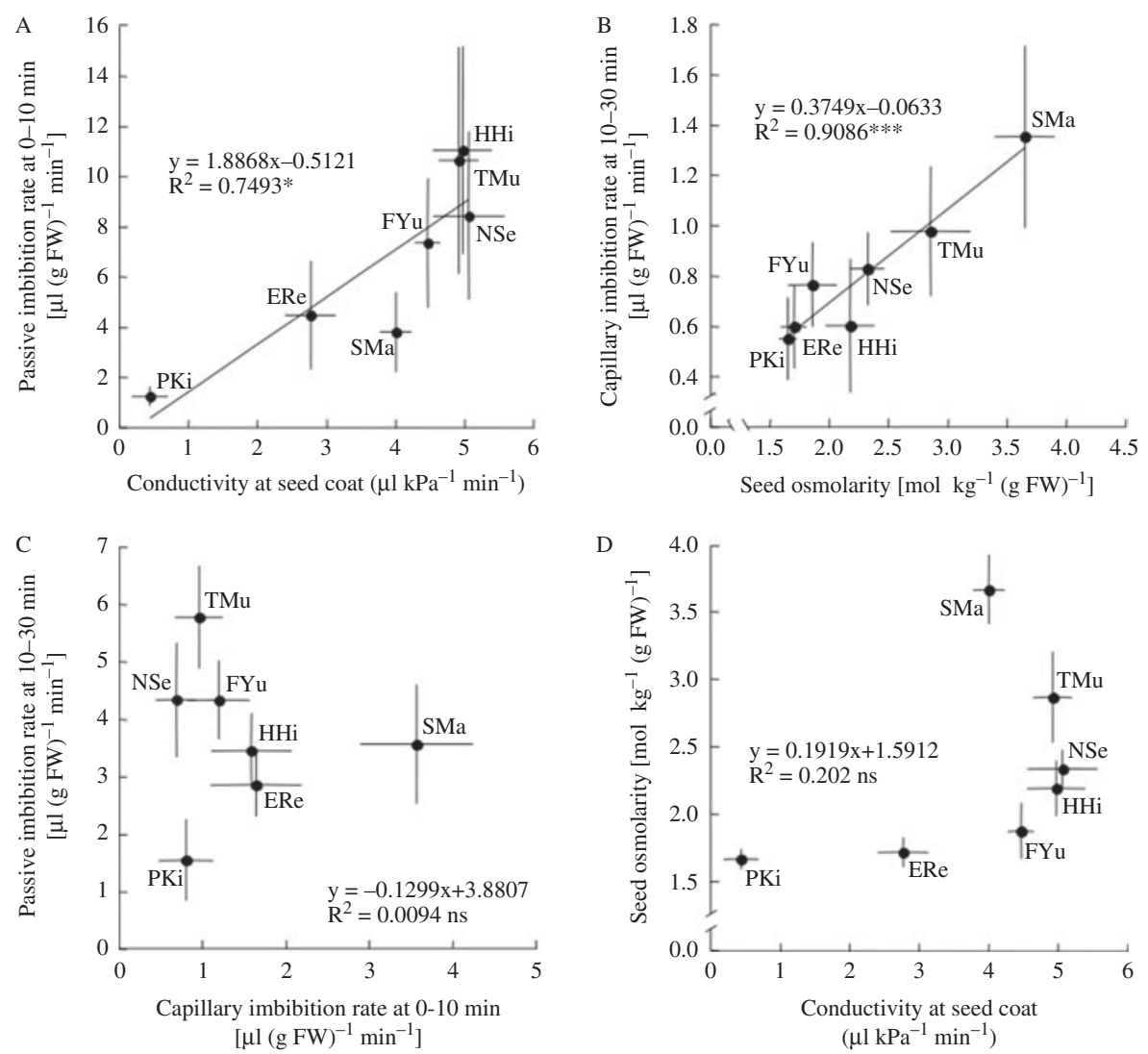

Figure 6. Relationships between the conductivity of the seed coat and passive imbibition rate at $0-10$ min (A), between seed osmolarity and capillary imbibition rate after 10-30 $\mathrm{min}(\mathrm{B})$, between capillary imbibition rate at $0-0$ min and passive imbibition rate at 10-30 min (C), and between the conductivity of the seed coat and seed osmolarity (D). Closed circle symbols represent each value with 3-10 replicates ( 5 for capillary imbibition rate, 6 for seed conductivity, 8 for passive imbibition rate, 10 for seed osmolarity), and the abbreviations of cultivars accompany these symbols. Bars show standard errors. Regression lines show the formulas marked by *** and * indicating significance at the 0.001 and 0.05 probability levels, respectively, by Pearson's correlation coefficients; ns denotes no significant difference.

treatments were all significant (Table 2). Further, flooding injury was detected in low-moisture seeds in certain cultivars, but not in high-moisture seeds in any cultivars (Fig. 2). These results indicate that highmoisture treatment could improve germination after flooding, as reported in past studies. It was also reported that the threshold for the effective moisture content to inhibit flooding injury was approximately 15\% (Toledo et al., 2010). On the other hand, Vertucci and Leopold (1984) suggested that imbibition damage of soybean seed was moderate between a seed moisture content of 8 and $24 \%$. From our results, we found that moisture contents ranging from $12.6 \%$ (Nakasennari) to $13.2 \%$ (Toyomusume) could also inhibit flooding injury (Table 2, Fig. 2). The results from the evaluation of soybean seed flooding injury after moisture treatments simply indicate that the cultivarspecific differences in flooding injury must appear in low-moisture seeds. The key factor affecting the flooding injury of soybean seeds is the seed waterabsorption rate - imbibition (Hou and Thseng, 1991;
Tian et al., 2005). For the next step, we focused on the behaviour of dried seeds.

\section{Flooding injury affected by the combination of both types of imbibition}

Low-moisture seeds showed remarkable symptoms of flooding injury in Toyomusume and Nakasennari, but not in Peking, Suzumaru or Hayahikari (Fig. 2). We could evaluate the former and the latter as susceptible and tolerant cultivars, respectively. These categories are almost in agreement with the evaluation for flooding tolerance in past research (Table 1). In lowmoisture seeds, the significant difference in survival among cultivars was first detected after $3 \mathrm{~h}$ of flooding $(P<0.001)$. Based on these results, we inferred that a specific biophysical event did not occur in seeds of tolerant cultivars but did occur in seeds of susceptible cultivars within $3 \mathrm{~h}$ of flooding, and this reduced survival. We defined the cultivar-specific survival 
reduction by flooding within $3 \mathrm{~h}$ as the vital reaction triggered by imbibition.

To quantify seed imbibition behaviour, we used the parameter of the water-absorption rate, further defined separately into passive and capillary rates. A past report evaluated the flooding tolerance of soybean seeds under complete flooding conditions that induced passive imbibition with submergence (Hou and Thseng, 1992), and another report investigated soybean seed imbibition from a substrate water supply associated with capillary imbibition (Nakayama and Komatsu, 2008). In an actual converted field, the complete flooding situation for seeds can be imagined to occur if heavy rain occurs just after seeding. However, just before and after the flooding situation, there should also be a slow, but constant, water supply via soil particles touching the seed surface. In other words, both behaviours, passive and capillary imbibition, could occur in soybean cultivation in a converted field. Therefore, we measured these imbibition rates separately, and evaluated each separately and their combination.

When soybean seeds experienced unhindered imbibition, water was absorbed from the whole seed surface (Ma et al., 2004), from a fixed specific region (McDonald et al., 1988; Pietrzak et al., 2002), or from a specific region that changed over time (Meyer et al., 2007). In a preliminary analysis of the imbibition according to every partial region of seed surfaces, a multiple comparison procedure with a Tukey-Kramer's test did not show significant differences among five separate seed surface regions (Fig. 1A) during $0-10 \mathrm{~min}$ of flooding for either passive imbibition $(P=0.227>0.1, n=56)$ or capillary imbibition $(P=0.913>0.1, n=35)$. Therefore, we concluded that the effect of region-specific imbibition on whole-seed imbibition would not be relevant, and averaged the imbibition measured from separate seed surface regions. Additionally, although we tried to carefully remove abnormal seeds during the first seed sorting, seeds with heterogeneous swelling were often observed under flooding. Probably, seeds with tiny cracks or wounds remained even after careful sorting, and water absorbance would be concentrated in the specific regions under constant water pressure. The methodology for the imbibition measurement that we adopted in the present study included checking for the appearance of a normal seed coat and averaging regional imbibition. These were done so that we might be able to avoid the risk of irregularities from abnormal seed coats.

Thus, we carefully measured two types of imbibition; however, there were no close relationships between the flooding tolerance of soybean seeds and either type of imbibition in our methods and samples. We analysed the balance of two imbibition rates (passive/capillary ratio, which was calculated as the passive imbibition rate at $10-30 \mathrm{~min} /$ capillary imbibition rate at $0-10 \mathrm{~min})$. This parameter showed a close relationship with cultivar-specific flooding tolerance (Fig. 5). The soybean cultivars that showed slower capillary imbibition, namely the susceptible Toyomusume and Nakasennari, nevertheless had faster passive imbibition, and therefore had a higher passive/capillary ratio. In contrast, soybean cultivars with a lower passive/capillary ratio were tolerant, i.e. Peking and Suzumaru. In this case, the slower passive imbibition in Peking and the faster capillary imbibition in Suzumaru seemed to lower the passive/capillary ratio (Figs 3, 4 and 5). From these results, we concluded that the reduced flooding injury of soybean seeds might be caused by their ability for capillary water absorbance, and for the restraint of forced water inflow under flooding, and that this complex behaviour was independently affected by the two types of imbibition (Fig. 6C), as reflected in the passive/capillary ratio.

\section{Two seed traits independently affect the two types of imbibition}

This study suggested that two different seed traits were independently linked to the two different types of imbibition behaviour. As a result, significant relationships were detected between the hydraulic conductivity of the seed coat and passive imbibition rate, and between the seed osmolarity and capillary imbibition rate (Fig. 6A and B). Furthermore, these two relationships were independent, since passive imbibition rate and seed osmolarity had no relation with capillary imbibition and hydraulic conductivity, respectively (Fig. 6C and D). Considering these two relationships with cultivar-specific traits, we could interpret that Peking, whose seed coat permeability was lower, had slower passive imbibition (Fig. 6A), and that Suzumaru, which had higher osmolarity, absorbed water positively (Fig. 6B). We could also hypothesize that the seed coat had a defensive role as the barrier for imbibition in the former example, and that the rich soluble substances induced the positive water-drawing capacity for imbibition in the latter example. The swelling ratio during moisture treatment was largest in Suzumaru (Table. 2) and must be linked with the high capacity for water influx. Actually, the swelling ratio had a significant positive correlation with the capillary imbibition rate $\left[R^{2}=0.6972\right.$ $(P=0.0194<0.05), n=7$, data not shown].

In general, soluble carbohydrates are thought to be the component mainly affecting the osmolarity of the extract solution from soybean cotyledons. Sucrose accounts for the largest part of the soybean cotyledons as a water-soluble monosaccharide, followed by stachyose and raffinose (Liu, 1997). Among the water-soluble polysaccharides in the cell wall of soybean cotyledons are the pectin-like structures, rhamnogalacturonans, with side chains of neutral 
carbohydrates (Nakamura et al., 2001). Although we did not identify the substances that affected seed osmolarity in this study, the carbohydrates described above might increase the seed osmolarity in some specific soybean cultivars.

An investigation using a pressure chamber reported that the soybean seed coats that were impermeable had five times lower hydraulic conductivity than permeable seed coats (Meyer et al., 2007). We also measured the hydraulic conductivity of seed coats with a modified pressure chamber method. In the present study, the region of the seed coat for measurement of hydraulic conductivity was limited to the abaxial surface (Fig. 1A, areas 5 and 6), because a flat region $3 \mathrm{~mm}$ in diameter was needed to fit the hole-size of the lid of the pressure chamber, and preparation of the disk was difficult for cultivars with smaller seeds, such as Peking and Suzumaru. Thus, the hydraulic conductivity of seed coats was limited to the abaxial surface; however, a close relationship between high conductivity and greater passive imbibition was shown. It is reasonable to assume that when the hydraulic conductivity of the seed coat was lower, passive imbibition was also smaller and, hence, the passive/capillary ratio tended to be lower, and the flooding tolerance became stronger. Clearly, seed coat resistance made water influx slow enough, so that the cotyledons would not break. However, the reason why seeds with a seed coat of high hydraulic conductivity showed a fast passive imbibition rate, remained unclear. Information about the traits of soybean seed coats related to hydraulic conductivity has already been reported. Imbibition induced the seed region of the seed coat not to adhere with the abaxial surface of the cotyledons (Chachalis and Smith, 2000; Nakayama and Komatsu, 2008). In addition, impermeable seed coats had fewer poreor crack-like structures than permeable seed coats (Yaklich et al., 1986; Ma et al., 2004). It was proposed that the cuticle that formed on the seed coat determined the permeability via the number of cracks (Ranathunge et al., 2010). Thus, seed hardness was influenced by the cuticle (Shao et al., 2007), the hemicelluloses (Mullin and $\mathrm{Xu}, 2001$ ) or the phenolics (Zhou et al., 2010). On the other hand, it has been suggested that the aleurone layer (Tian et al., 2005) or inner layer (Koizumi et al., 2008) in the seed coat affected the permeability.

From the present study we conclude that: (1) the cultivar-specific seed flooding tolerance originates from decreasing survival of low-moisture seeds in susceptible cultivars; (2) the decreasing survival after $3 \mathrm{~h}$ of flooding is due to the balance of two types of imbibition rate (passive/capillary imbibition rate); (3) the two imbibition rates would be influenced independently by the hydraulic conductivity of the seed coat and by seed osmolarity, respectively. We will investigate in detail the positional relationship between the seed coat and the cotyledons, and the linkage between the structure of the seed coat and hydraulic conductivity. Understanding of the mechanism causing soybean seed flooding injury will be advanced by these basic investigations.

\section{Acknowledgements}

Appreciation is extended to the gene bank of the National Institute of Agrobiological Science for providing experimental seeds (user number: 2759); and to Professor J. Abe of the Research Faculty of Agriculture, Hokkaido University for advice on the experimental progress. We also thank Mr S. Ichikawa of the Field Science Centre for the Northern Biosphere, Hokkaido University, for assistance in seed multiplication.

\section{Financial support}

This study was supported by a Grant-in-Aid for Scientific Research from the Japan Society for the Promotion of Science (grant number: 24658013).

\section{Conflicts of interest}

None.

\section{References}

Arihara, J., Tian, X., Nakayama, N., Saito, Y. and Kanno, A. (2000) Crop specific difference in growth and yield caused by low oxygen stress during germination. p. 59 in Abstracts of the Third International Crop Science Congress. Hamburg, Germany.

Chachalis, D. and Smith, M.L. (2000) Imbibition behavior of soybean (Glycine $\max$ (L.) Merrill) accessions with different testa characteristics. Seed Science and Technology 28, 321-331.

Hou, F.F. and Thseng, F.S. (1991) Studies on the flooding tolerance of soybean seed: varietal differences. Euphytica 57, 169-173.

Hou, F.F. and Thseng, F.S. (1992) Studies on the screening technique for pre-germination flooding tolerance in soybean. Japanese Journal of Crop Science 61, 447-453.

Ishibashi, Y., Nakamoto, H., Hamabe, Y., Zheng, S.-H., Nabeta, M. and Iwaya-Inoue, M. (2005) Analysis of imbibition damage in soybean seed. Cryobiology and Cryotechnology 51, 99-104.

ISTA (International Seed Testing Association). (1985) International rules for seed testing. Seed Science and Technology 13, 299-355.

Kato, M., Minamida, K., Tojo, M., Kokuryu, T., Hamaguchi, H. and Shimada, S. (2013) Association of Pythium and Phytophthora with pre-emergence seedling damping-off of soybean growth in a field converted from a paddy field in Japan. Plant Production Science 16, 95-104. 
Koizumi, M., Kikuchi, K., Isobe, S., Ishida, N., Naito, S. and Kano, H. (2008) Role of seed coat in imbibing soybean seeds observed by micro-magnetic resonance imaging. Annals of Botany 102, 343-352.

Krishnan, P., Joshi, D.K., Nagarajan, S. and Moharir, A.V. (2004) Characterization of germinating and non-viable soybean seeds by nuclear magnetic resonance (NMR) spectroscopy. Seed Science Reseach 14, 355-362.

Liu, K.S. (1997) Chemistry and nutritional value of soybean components. pp. 25-113 in Liu, K.S. (Ed.) Soybean chemistry, technology and utilization. New York, Chapman \& Hall.

Ma, F., Cholewa, E., Mohamed, T., Peterson, C.A. and Gijzen, M. (2004) Cracks in the palisade cuticle of soybean seed coats correlate with their permeability to water. Annals of Botany 94, 213-228.

Matsuo, N., Takahashi, M., Nakano, H., Fukami, K., Tsuchiya, S., Morita, S., Kitagawa, H., Nakano, K., Nakamoto, H. and Tasaka, K. (2013) Growth and yield response of two soybean cultivars grown under controlled groundwater level in southern Japan. Plant Production Science 16, 84-94.

McDonald, M.B., Vertucci, C.W. and Roos, E.E. (1988) Soybean seed imbibition: water absorption by seed parts. Crop Science 28, 993-997.

Meyer, C.J., Steudle, E. and Peterson, C.A. (2007) Patterns and kinetics of water uptake by soybean seeds. Journal of Experimental Botany 58, 717-732.

Ministry of Agriculture, Forestry and Fisheries of Japan. (2005) Aiming at stability and high yield of soybean production. Agriculture, Forestry and Fisheries Research Council, Agriculture and Forestry Fisheries Research and Development Report 13. Published online in Japanese. Available at: http://www.s.affrc.go.jp/docs/report/ pdf/no13.pdf (accessed 3 June 2013).

Ministry of Agriculture, Forestry and Fisheries of Japan. (2010) Basic plan for food, agriculture and rural areas. Published online in Japanese. Available at: http:/ / www. maff.go.jp/j/keikaku/k_aratana/pdf/kihon_keikaku_ 22.pdf (accessed 3 June 2013).

Ministry of Agriculture, Forestry and Fisheries of Japan. (2012) Soybean planting area in 2012 (dry yield). Statistics of Agriculture, Forestry and Fisheries, Department of minister's secretariat statistics. Published online in Japanese. Available at: http://www.maff.go.jp/j/tokei/ kouhyou/sakumotu/menseki/pdf/sakutuke_daizu_12. pdf (accessed 3 June 2013).

Mullin, W.J. and Xu, W. (2001) Study of soybean seed coat components and their relationship to water absorption. Journal of Agricultural Food Chemistry 49, 5331-5335.

Muramatsu, N., Kokubun, M. and Horigane, A. (2008) Relation of seed structure to soybean cultivar difference in pre-germination flooding tolerance. Plant Production Science 11, 434-439.

Nakamura, A., Furuta, H., Maeda, H., Nagamatsu, Y. and Yoshimoto, A. (2001) Analysis of structural components and molecular construction of soybean soluble polysaccharides by stepwise enzymatic degradation. Bioscience Biotechnology and Biochemistry 65, 2249-2258.

Nakayama, N. and Komatsu, S. (2008) Water uptake by seeds in yellow-seeded soybean (Glycine max (L.) Merrill) cultivars with contrasting imbibition behaviors. Plant Production Science 11, 415-422.
Obendorf, R.L. and Hobbs, P.R. (1970) Effect of seed moisture on temperature sensitivity during imbibition of soybean. Crop Science 10, 563-566.

Oyoo, E.M., Benitez, R.E., Matsuura, H. and Takahashi, R. (2010) QTL analysis of seed coat cracking in soybean. Crop Science 50, 1230-1235.

Pietrzak, L.N., Fregeau-Reid, J., Chatson, B. and Blackwell, B. (2002) Observations on water distribution in soybean seed during hydration processes using nuclear magnetic resonance imaging. Canadian Journal of Plant Science 82, 513-519.

Ranathunge, K., Shao, S., Qutob, D., Gijzen, M., Peterson, C.A. and Bernards, M.A. (2010) Properties of the soybean seed coat cuticle change during development. Planta 231, $1171-1188$.

Sayama, T., Nakazaki, T., Ishikawa, G., Yagasaki, K., Yamada, N., Hirota, N., Hirata, K., Yoshikawa, T., Saito, H., Teraishi, M., Okumoto, Y., Tsukiyama, T. and Tanisaka, T. (2009) QTL analysis of seed-flooding tolerance in soybean (Glycine max [L.] Merr.). Plant Science 176, 514-521.

Scott, H.D., Deangulo, J., Daniels, M.B. and Wood, L.S. (1989) Flood duration effects on soybean growth and yield. Agronomy Journal 81, 631-636.

Shao, S., Meyer, C.J., Ma, F., Peterson, C.A. and Bernards, M.A. (2007) The outermost cuticle of soybean seeds: chemical composition and function during imbibition. Journal of Experimental Botany 58, 1071-1082.

Tian, X.-H., Nakamura, T. and Kokubun, M. (2005) The role of seed structure and oxygen responsiveness in pre-germination flooding tolerance of soybean cultivars. Plant Production Science 8, 157-165.

Toledo, M.Z., Cavariani, C., França-Neto, J. de B. and Nakagawa, J. (2010) Imbibition damage in soybean seeds as affected by initial moisture content, cultivar and production location. Seed Science and Technology 38, 399-408.

VanToai, T.T., Hoa, T.T.C., Hue, N.T.N., Nguyen, H.T., Shannon, J.G. and Rahman, M.A. (2010) Flooding tolerance of soybean [Glycine max (L.) Merr.] germplasm from southeast Asia under field and screen-house environments. The Open Agriculture Journal 4, 38-46.

Vertucci, C.W. and Leopold, A.C. (1984) Bound water in soybean seed and its relation to respiration and imbibitional damage. Plant Physiology 75, 114-117.

Weitbrecht, K., Müller, K. and Leubner-Metzger, G. (2011) First off the mark: early seed germination. Journal of Experimental Botany 62, 3289-3309.

Woodstock, L.W. and Taylorson, R.B. (1981) Soaking injury and its reversal with polyethylene glycol in relation to respiratory metabolism in high and low vigor soybean seeds. Physiologia Plantarum 53, 263-268.

Wuebker, E.F., Mullen, R.E. and Koehler, K. (2001) Flooding and temperature effects on soybean germination. Crop Science 41, 1857-1861.

Yaklich, R.W., Vigil, E.I. and Wergin, W.P. (1986) Pore development and seed coat permeability in soybean. Crop Science 26, 616-624.

Zhou, S., Sekizaki, H., Yang, Z., Sawa, S. and Pan, J. (2010) Phenolics in the seed coat of wild soybean (Glycine soja) and their significance for seed hardness and seed germination. Journal of Agricultural and Food Chemistry 58, 10972-10978. 